\title{
Effects of propofol on cerebral oxygenation during cardiopulmonary bypass in children
}

Jacques Gerard LeBlanc MD FRCSC, Derek Blackstock MB FRCPC, Andrew J. Macnab MD FRCPC, Faith Gagnon HBSc, Roy Gagnon DT, Jennifer Russell MD FRCPC, Todd Ring BSc

Purpose: Neurologic complications occur following cardiopulmonary bypass surgery. We conducted a randomized, controlled, single-blind study to determine the effect of propofol on the redox status of cytaa ${ }_{3}$, and to evaluate its potential for decreasing neurologic complications.

Methods and Materials: Twenty-four children (median age: $3.3 \mathrm{yr}$; median weight: $14.4 \mathrm{~kg}$ ) scheduled for elective cardiopulmonary bypass surgery were assigned to either the experimental group (Group P, given sufficient propofol to eliminate brain electrical activity as measured on EEG (i.e. burst suppression)) or the control group (Group C, no propofol). Near infrared spectroscopy data were collected at one-second intervals throughout the surgical procedures. Pre- and postoperative neurologic examinations were completed by a physician blinded to the group to which the patient was assigned. Change in cytochrome aa data at I0-min intervals $(10,20,30,40$ $\mathrm{min}$ ) following start of bypass were compared between groups by repeated measures analysis of variance.

Results: The patterns of change in redox state of cytochrome were different between the two groups $P<$ 0.002). The pattern of change within Group P was similar to that in hypothermic patients in Group C. There were correlations between change in cytaa ${ }_{3}$ redox status and temperature in the control subjects. There were no gross neurologic complications in either group.

Conclusions: Propofol appears to stabilize the energy supply/demand equilibrium of the brain during cardiopulmonary bypass surgery and thus theoretically could reduce the incidence or severity of neurologic complications.

Objectif : Des complications neurologiques peuvent survenir à la suite de circulation extracorporelle (CEC) pendant une intervention chirurgicale. Nous avons réalisé une étude randomisée, contrôlée et à l'insu, afin de déterminer l'effet du propofol sur l'état redox du cytochrome aa ${ }_{3}$ et d'évaluer sa capacité à réduire les complications neurologiques.

Méthode : L'étude a porté sur 24 enfants (âge moyen : 3,3 ans; poids moyen : | 4,4 kg) qui devaient subir une intervention avec CEC. Ils ont reçu, dans le groupe expérimental P, suffisamment de propofol pour éliminer l'activité électrique cérébrale comme l'indiquait l'EEG (c.-à-d. la suppression des bouffées du tracé EEG). Le second groupe, témoin (T), n'a pas reçu de propofol. Les données spectrographiques près de l'infrarouge ont été recueillies à une seconde d'intervalle tout au long de l'opération. Un examen neurologique préopératoire et postopératoire a été fait par un médecin impartial. La modification des données sur le cytochrome aa $a_{3}$ enregistrées à 10 min d'intervalle (I0,20,30, $40 \mathrm{~min}$ ) après le début de la CEC, a été comparée entre les groupes par des analyses de variance pour mesures répétées.

Résultats : Les modèles de changement d'état redox du cytochrome ont été différents d'un groupe à l'autre ( $P$ $<0,002)$. Le modèle de changement dans le groupe $\mathrm{P}$ a été similaire à celui qu'on a observé chez les patients hypothermiques du groupe $T$. On pouvait établir des corrélations entre le changement d'état du cytochrome aa ${ }_{3}$ et la température chez les sujets témoins. Aucune complication neurologique importante n'est survenue dans un groupe ou l'autre.

Conclusion : Le propofol semble maintenir l'équilibre entre l'offre et la demande d'énergie cérébrale pendant une intervention chirurgicale avec circulation extracorporelle. II pourrait ainsi réduire, en théorie, l'incidence ou la sévérité des complications neurologiques.

From the Division of Cardiovascular and Thoracic Surgery, Children's and Women's Hospital of British Columbia, University of British Columbia, Vancouver, BC, Canada.

Address correspondence to: Dr. Jacques LeBlanc, Head, Division of Cardiovascular and Thoracic Surgery, 3G65, Children's and

Women's Hospital of British Columbia, 4480 Oak Street, Vancouver, B.C. V6H 3V4 Canada. Phone: 604-875-4324; Fax: 604-875-3159;

E-mail: jleblanc@dowco.com

This study was funded by a grant from The Hospital for Sick Children Foundation, External Grants Program, Toronto, Ontario. Accepted for publication on July 6, 2000. 


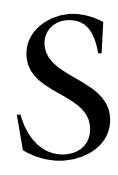

INCE the inception of open heart surgery more than $40 \mathrm{yr}$ ago, enormous strides have been made in improving cardiopulmonary bypass $(\mathrm{CPB})$ technology and operative techniques with a resultant progressive decrease in mortality and morbidity. While these advances have improved overall surgical outcome, repair of congenital cardiac lesions performed during hypothermic cardiopulmonary bypass with or without total circulatory arrest is still associated with considerable short- and long-term neurological damage. ${ }^{1-5}$ The reported incidence of neurological complications of open heart surgery varies widely ranging from 7 to $61 \%$ for transient and from 1.6 to $23 \%$ for permanent complications. ${ }^{6,7}$ Recent reports concerning infants undergoing cardiopulmonary bypass surgery with deep hypothermia and circulatory arrest puts the figure at $25 \%$ for permanent neuropsychological injury. ${ }^{8}$

Neurologic damage associated with cardiac surgery in children is partly related to inadequate tissue oxygenation. Therefore, techniques designed to optimize cerebral oxygenation are continually being developed. The goals of these "cerebral protection" techniques are to maximize oxygen availability and/or minimize the brain's requirement for oxygen. Maximizing oxygen availability involves optimizing the oxygen saturation of the blood, and cerebral blood flow. Minimizing the oxygen requirement involves decreasing the metabolic rate in the brain. This is achieved by cooling (hypothermia) or by decreasing the cerebral electrical activity with anesthetic agents. Barbiturates and thiopental can achieve electrical silence on electroencephalography (EEG), but the doses required are large, and the side effects, particularly the effects on blood pressure, are undesirable. ${ }^{9,10}$

Propofol is a sterically-hindered phenol (2,6-diisopropylphenol) that was introduced in 1989. ${ }^{11}$ It has a very short half-life with a short postoperative recovery period. It also appears to have anti-emetic and positive mood-altering properties ${ }^{12}$ making its use as an anesthetic agent attractive. Propofol's ability to eliminate cerebral electrical activity, and thereby decrease the metabolic demands of the brain, is its principal attraction in cardiopulmonary bypass surgery. ${ }^{11,12}$ However, propofol also appears to decrease cerebral blood flow, ${ }^{13,14}$ although it does not appear to alter lactate and glucose metabolism. ${ }^{14}$

In adults undergoing cardiopulmonary bypass surgery, propofol, used to achieve electrical silence on EEG (burst suppression), reduces cerebral blood flow, oxygen delivery and metabolic rate. ${ }^{15}$ In children undergoing cardiopulmonary bypass surgery, the use of propofol to achieve electrical silence was associated with decreased systemic oxygen uptake (i.e. decreased metabolic rate at the terminal end of the electron transfer chain), with decreased glucose and cortisol concentrations, ${ }^{16}$ but no increase in serum lactate concentrations. ${ }^{17}$

There have been no studies in children receiving propofol to evaluate the status of cerebral oxgenation at the cellular level. Using the recently-developed, non-invasive technique of near infrared spectroscopy (NIRS), changes in the concentrations of three substances (chromophores) that absorb light in the near infrared region can be monitored continuously. ${ }^{18-20}$ These chromophores, which are indicators of tissue oxygenation, are oxy- and deoxy- hemoglobin $\left(\mathrm{HbO}_{2}\right.$ and $\mathrm{Hb}$, respectively) and the oxidized form of cytochrome $\mathrm{aa}_{3}$ (cyt). Cytochrome $\mathrm{aa}_{3}$, embedded in the wall of the mitochondria within the cells, is the terminal enzyme in the electron transfer chain, and thus indicates the status of oxygenation at the cellular, rather than circulatory, level. Changes in the concentration of oxidized cytochrome $\mathrm{aa}_{3}$ represent a shift in the equilibrium between oxidized and reduced cytochrome $\mathrm{aa}_{3}$. As in any other chemical equilibrium, this may reflect changes in a variety of factors including concentration of the active components (in this case oxygen and reduced cytochrome c), $\mathrm{pH}$, and temperature. In essence, measuring cytochrome aa monitors cellular wellbeing as affected by oxygen delivery, energy supply (glucose or other substrate), $\mathrm{pH}$, and temperature.

This study was designed to test the hypothesis that propofol, administered to maintain cerebral electrical silence during cardiopulmonary bypass surgery would alter the magnitude or rate of change of redox status of cytochrome $\mathrm{aa}_{3}$.

\section{Method}

This prospective, randomized, single-blinded study was approved by the University of British Columbia Ethics Review Board. Children who were scheduled for elective repair of atrial or ventricular septal defects (ASD or VSD), who were $<16$ yr old, and whose parents provided informed consent, were randomly assigned to either the experimental group (Group P) or control group (Group C). Children with a history of seizures, and children with Downs syndrome were excluded from the study. There were 24 children enrolled in the study, 11 in Group P and 13 in Group C.

Group P received sufficient propofol (see below) to eliminate cerebral electrical activity approximately two minutes prior to cooling. Group $\mathrm{C}$ did not receive propofol. The experiment did not use a double blinded design since the anesthesiologist administering the 
propofol needed to be able to adjust the dosage to maintain cerebral electrical silence. Management of $\mathrm{CPB}$ was similar in both groups, and hypothermia was used as required. Surgical procedures were not dictated by the protocol.

Both groups received the same anesthetic protocol with the exception of the propofol. Anesthesia was induced with 3 to $6 \mathrm{mg} \cdot \mathrm{kg}^{-1}$ thiopental, and pancuronium, vecuronium or rocuronium was given as a muscle relaxant. Anesthesia was maintained with 25 to $100 \mu \mathrm{g} \cdot \mathrm{kg}^{-1}$ fentanyl and isoflurane up to $2 \%$ at the anesthesiologist's discretion. Nitrous oxide was not used, since it has been shown to increase cerebral metabolic rate. ${ }^{16}$ The $\mathrm{pH}$ was not actively managed, but allowed to change with temperature.

Near infrared spectroscopy (NIRS) was initiated in the operating room following induction of anesthesia. The method used was similar to that described by other investigators. ${ }^{18,21,22}$ We used a Hamamatsu NIRO 500 (Hamamatsu Photonics KK, Hamamatsu City, Japan), a commercially available near infrared spectroscopy unit which emits light at four wave lengths $(777,828,848$, and $910 \mathrm{~nm})$ from laser diodes and directs them into the head through a fibreoptic bundle. The optodes were positioned $30 \mathrm{~mm}$ apart, laterally over the frontal region to avoid potential interference from the sagittal sinus and temporalis muscle. Light emerging from the head was conveyed through another fibreoptic bundle to a photomultiplier tube. The ends of the fibres (optodes) were fixed to the scalp with elastic tape. Background light was excluded by an opaque bonnet.

Cerebral oxygenation (via NIRS), temperature (nasopharyngeal and rectal), 2-lead EEG, central venous pressure, end tidal $\mathrm{CO}_{2}$, and blood pressure were monitored continuously throughout the procedure. Pulmonary artery or left atrial pressure were monitored when required.

In Group P, two minutes before cooling, a bolus of 4 $\mathrm{mg} \cdot \mathrm{kg}^{-1}$ propofol was given, followed by an infusion of 50 to $350 \mu \mathrm{g} \cdot \mathrm{kg}^{-1} \cdot \mathrm{min}^{-1}$, sufficient to maintain electrical silence on EEG at the target temperature. The infusion was discontinued at the beginning of rewarming.

Throughout the surgical procedure, event times were recorded manually by the anesthesiologist and the NIRS operator. Events were also recorded by placing a marker in the NIRS data stream. NIRS data were recorded using the manufacturer's software, as raw optical densities and then converted to changes in concentration using a standard algorithm, ${ }^{23}$ and a consistent differential pathlength of 5.0 , a median value of those reported in the literature for adults $(6.26 \pm 0.88)$ and infants $(3.78 \pm 31){ }^{24,25}$ The NIRS data were eval- uated in terms of absolute change in concentration of oxidized cytochrome aa $\mathrm{a}_{3}$. Data manipulation, graphing, and statistics were conducted using QuattroPro8.0.

A standard clinical neurological examination was conducted by a pediatrician blinded to group assignment. The neurological assessment was completed as part of the preoperative evaluation and at the time of the first out-patient follow-up at approximately three months. Neuropsychologic testing was not done.

The groups were compared according to age, type of surgery, duration of cardiopulmonary bypass, and sex.

Because NIRS provides absolute change, the zero point is arbitrary. For comparison, data sets were translated, without rotation or scale change, to a reference point of the period immediately prior to initiating bypass. We used the 100 data points prior to bypass, ignoring the data spike associated with compression and release of the carotids, as the baseline. This was done for $\mathrm{Hb}, \mathrm{HbO}_{2}, \mathrm{HbSum}\left(\mathrm{Hb}+\mathrm{HbO}_{2}\right)$, and cytochrome $\mathrm{aa}_{3}$. Data were plotted with identical scale factors for comparison. Figures for cytochrome $\mathrm{aa}_{3}$ are shown with a 10 -point moving average, but statistics were performed on raw data. The standard deviation and $95 \%$ confidence intervals were determined and plotted. Repeated measures analysis of variance was conducted for data at $0,10,20,30$ and 40 min of the bypass period. In addition, data for the period 10 to $40 \mathrm{~min}$ following onset of bypass were averaged for each subject and the averages compared between groups. Because the duration of bypass varied, a 40 min period was chosen to avoid the time interval during discontinuation of bypass where multiple variables inevitably affect data. An of $P<0.05$ was accepted as significant.

\section{Results}

Basic demographic and surgical information is presented in the Table. The groups were similar with the exception of bypass duration, with the greater duration in Group P.

There was no difference in the pattern of change in oxygenated hemoglobin concentration $\left(\mathrm{HbO}_{2}\right)$ throughout bypass between the groups (Figure 1). Both groups demonstrated a decrease in $\mathrm{HbO}_{2}$ of about $10 \mu \mathrm{MOL}$ at the onset of bypass. There was no difference in the pattern of change in deoxygenated hemoglobin $(\mathrm{Hb})$ (Figure 2) which demonstrated a small initial rise of about $2.5 \mu \mathrm{MOL}$ tissue followed by decrease to about $3 \mu \mathrm{MOL}$ tissue below baseline. There was also no difference between groups in the pattern of the sum of $\mathrm{HbO}_{2}+\mathrm{Hb}(\mathrm{HbSum})$, an indicator of total cerebral blood volume (Figure 3 ). 
TABLE

\begin{tabular}{lll}
\hline & Group $P$ & Group C \\
\hline number of patients & 11 & 13 \\
male:female ratio & $3: 8$ & $6: 7$ \\
$\begin{array}{l}\text { age (mean } \pm \text { SD) } \\
\text { type of surgery }\end{array}$ & $4.7 \pm 3.7$ & $3.4 \pm 2.6$ \\
& $\begin{array}{l}\text { ASD 8; VSD 1; } \\
\text { ASD /VSD 1; }\end{array}$ & VSD 10; \\
mitral valve 1 & \\
$\begin{array}{l}\text { duration of bypass (mean } \pm \text { SD) } \\
\begin{array}{l}\text { in minutes } \\
\text { duration of cross-clamp }\end{array}\end{array}$ & $78 \pm 40^{*}$ & $54 \pm 18$ \\
$\begin{array}{l}\text { (mean } \pm \text { SD) min } \\
\text { hematocrit during bypass } \\
\text { minimum temperature } \\
\text { during bypass }\end{array}$ & $38 \pm 25$ & $28 \pm 16$ \\
\hline
\end{tabular}

${ }^{*} P<0.05$ for difference between groups

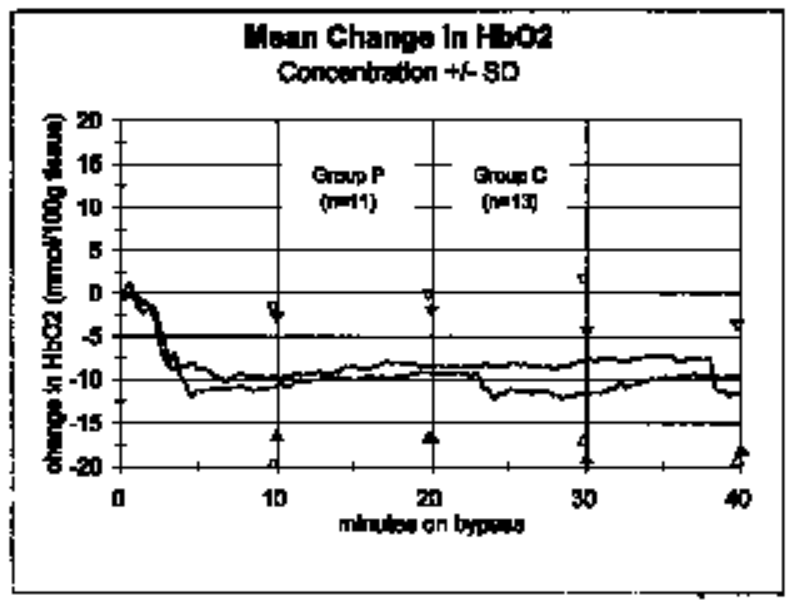

FIGURE I Summary of mean change in $\mathrm{HbO}_{2}$ concentration indicating no difference between the propofol and control groups (propofol group - black markers, control group - open markers).

There was a difference in the mean change in redox status of cytochrome $\mathrm{aa}_{3}$ between groups during bypass (Figure 4 ). The means of the cytochrome $\mathrm{aa}_{3}$ changes, which were normally distributed in the period from $10 \mathrm{~min}$ to $40 \mathrm{~min}$ of bypass, were different between the groups $(P<0.005, \mathrm{t}$ test of mean values in this period). To further elucidate this difference, subjects were sub-grouped by minimum temperature during bypass: normothermic $\left(35^{\circ} \mathrm{C}\right.$ or higher $)$, mild hypothermia $\left(32-34^{\circ} \mathrm{C}\right)$, and moderate hypothermia $\left(28\right.$ to $\left.32^{\circ} \mathrm{C}\right)$. There were no significant differences among the propofol sub-groups (Figure 5) (ANOVA

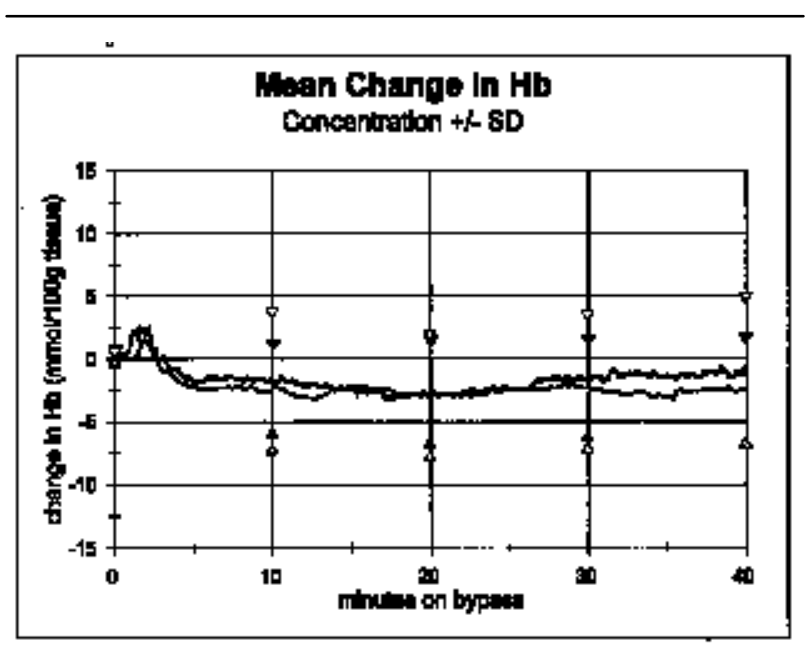

$\overline{\text { FIGURE } 2 \text { Summary of mean change in Hb concentration indi- }}$ cating no difference between the propofol and control groups (propofol group - black markers, control group - open markers).

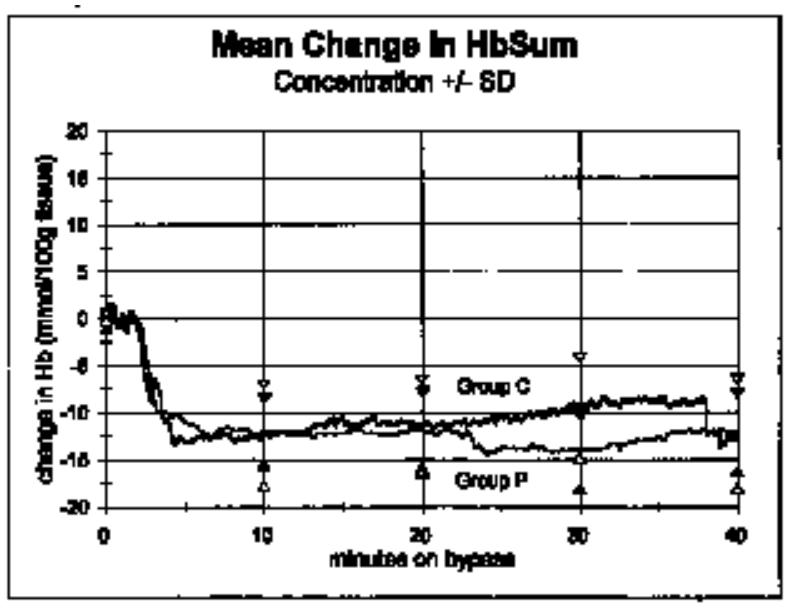

FIGURE 3 Summary of mean change in HbSum concentration indicating no difference between the propofol and control groups (propofol group - black markers, control group - open markers).

for differences at times $10,20,30$ and $40 \min P>$ 0.05 ), but the control sub-groups differed significantly with temperature (Figure 6). In the control subjects at normothermia, cytochrome $\mathrm{aa}_{3}$ increased and steadily after initiating bypass. This pattern was also apparent in one patient in the mild hypothermia group $\left(33^{\circ} \mathrm{C}\right)$. At mild and moderate hypothermia there was a decrease of about $1 \mu \mathrm{MOL}$ tissue followed 


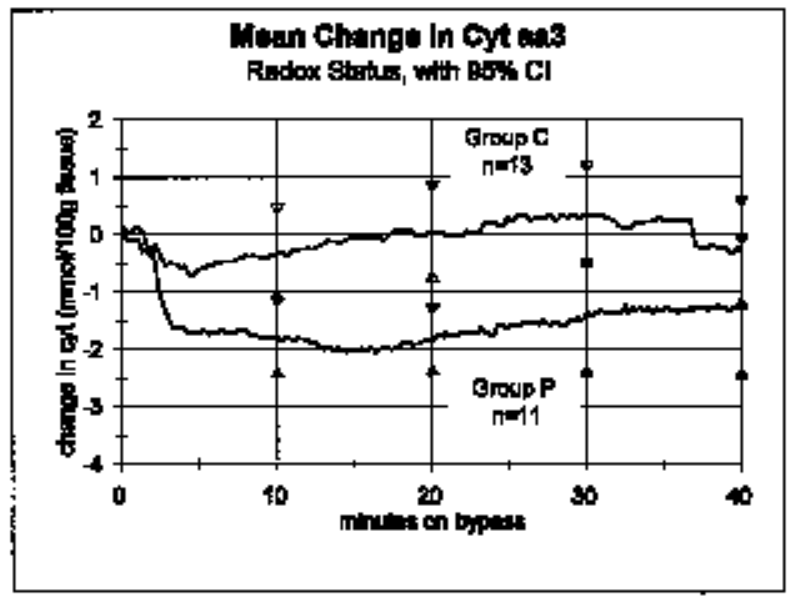

FIGURE 4 Summary of mean change in cytochrome redox status indicating a difference between the propofol and control groups (propofol group - black markers, control group - open markers). Markers indicate the $95 \%$ confidence interval .

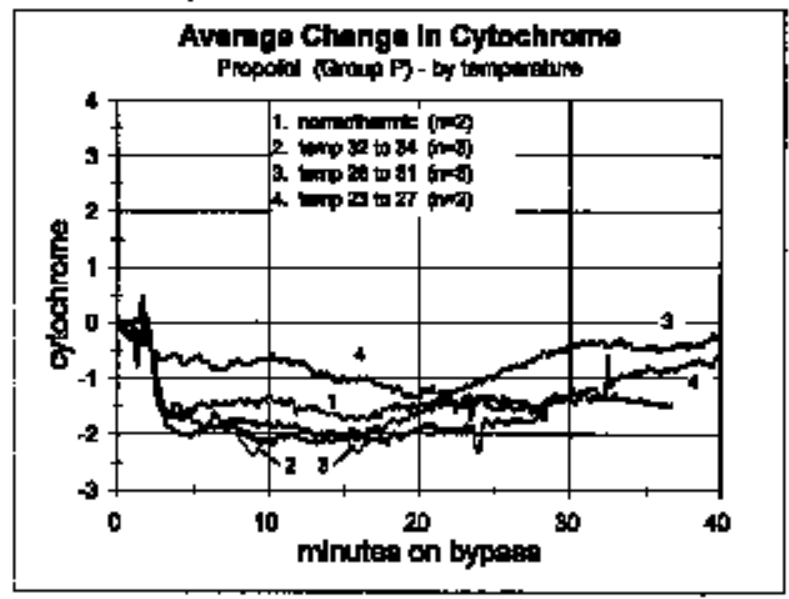

FIGURE 5 Average change in cytchrome redox status in the propofol group, with subjects subgrouped by minimum temperature during bypass, indicating no significant differences between subgroups.

by a return to baseline or above before decreasing with rewarming.

We determined the correlation between temperature and change in cytochrome $a_{3}$ redox status during cooling and rewarming. In Group P (propofol) there was little correlation between temperature and change in cytochrome $\mathrm{aa}_{3}(\mathrm{r}=0.17)$, but in Group C
FIGURE 6 Average change in cytchrome redox status in the control group, with subjects subgrouped by minimum temperature during bypass, indicating significant differences between subgroups.

(control) there was a correlation between temperature and change in cytochrome $\mathrm{aa}_{3}(\mathrm{r}=0.75)$.

The EEGs were graded as "silent", "quiet", or "active" (i.e., 0, 1, or 2) during the bypass period. The incidences were different between groups: all Group P subjects scored 0 , whereas in Group C only one subject scored 0 (a patient cooled to 29 degrees), six scored 1 , four scored 2, and two did not have EEGs recorded.

There was no difference in neurologic outcome, either in the immediate postoperative period, or at three month follow-up.

Discussion

We showed a difference in the pattern of change in redox status of cytochrome $a_{3}$ between the patients who received propofol and those who did not. Those who received propofol had a more stable pattern, particularly when compared with normothermic controls.

We demonstrated a decrease in concentration of $\mathrm{HbO}_{2}$ of $10 \mu \mathrm{MOL}$ and a decrease in concentration $\mathrm{Hb}$ of $3 \mu \mathrm{MOL}$ at the institution of bypass. Both changes remained constant throughout the bypass period in both groups. The change is likely largely due to the dilution effect of the perfusion pump priming solution, and is likely reversed on hemo-concentration at the termination of the bypass period. This was not a factor examined in this study.

Other investigators have reported changes seen on near infrared spectroscopy during $\mathrm{CPB},{ }^{21,22,26-28}$ but 
few have reported changes in cytochrome $\mathrm{aa}_{3}{ }^{21,27}$ Although changes in the redox status of cytochrome aa are potentially the most relevant, the cytochrome $\mathrm{aa}_{3}$ data are not often reported for several reasons. Because of the equipment used (the number of wavelengths employed), cytochrome $\mathrm{aa}_{3}$ data are not always available. In addition, the cytochrome $\mathrm{aa}_{3}$ signal is quite noisy unless the photon return rate is high. Thirdly, the validity of the cytochrome $\mathrm{aa}_{3}$ signal has been questioned, primarily because the changes observed often were not what were expected intuitively, and there have been suggestions that the cytochrome $\mathrm{aa}_{3}$ signal is affected by changes in concentration of $\mathrm{Hb}$ and/or $\mathrm{HbO}_{2}$, sometimes termed "cross-talk". ${ }^{29}$ Finally, interpretation of changes in cytochrome $\mathrm{aa}_{3}$ is complex because it represents a change in equilibrium which may reflect fluctuation in any of several factors, and the balance between them, including: oxygen supply, glucose or other substrate supply, $\mathrm{pH}$, temperature, and rate of reactions at other levels of the electron transfer chain. This latter problem may be overcome in the near future by new technology and computer modelling that has, to date, used in vitro data, ${ }^{30,31}$ but which may begin incorporating in vivo data. However, the consensus of the 1997 Royal Society Discussion Meeting on NIRS of Living Tissues was that cytochrome $\mathrm{aa}_{3}$ measurement by NIRS is a valid entity. ${ }^{31}$

In this study, we collected cytochrome $\mathrm{aa}_{3}$ data, we obtained clear signals, and there was no "cross-talk" between signals since the patterns of change of cytochrome $\mathrm{aa}_{3}$ were different between the study groups, but those for hemoglobin were not different between groups. We believe that our observation of a difference in change in redox status of cytochrome $\mathrm{aa}_{3}$ during cardiopulmonary bypass between patients receiving and not receiving propofol to a level of burst suppression substantiates the validity of the cytochrome $a_{3}$ data.

We compared our findings with those reported previously by Greeley et al. ${ }^{2}$ That team used a NIR spectroscope, constructed in their own laboratory with four wavelengths, to study 15 pediatric subjects before, during, and after deep hypothermic $\left(18^{\circ} \mathrm{C}\right)$ cardiopulmonary bypass. They used a fentanyl/midazolam anesthetic protocol, and compared patients who had bypass with continuous flow bypass with those who had circulatory arrest. With continuous cardiopulmonary bypass, $\mathrm{HbO}_{2}$ and $\mathrm{Hb}$ decreased and remained relatively stable throughout the bypass period. This pattern was observed in both groups in our study. The decreases are likely largely due to the dilution effect of the perfusion pump priming solution, likely reversed on hemoconcentration at the termination of the bypass period. This was not a factor examined in this study.
Cytochrome $\mathrm{aa}_{3}$ redox status was also reported by Greeley. In that study, in which patients were much more hypothermic than in our study, cytochrome aa ${ }_{3}$ became less oxidized at the onset of bypass and remained in equilibrium until rewarming. This decrease in cytochrome $\mathrm{aa}_{3}$ redox status and subsequent equilibrium are similar to our findings in the group that received propofol. We have not compared the absolute magnitude of the changes between studies because Greeley's data are reported as changes in optical density rather than changes in absolute concentration. In our control group, at warmer temperatures and without propofol, cytochrome $\mathrm{aa}_{3}$ became progressively more oxidized throughout the procedure, which indicates that cytochrome $\mathrm{aa}_{3}$ is not in stable equilibrium in this group. During rewarming, Greeley reported a further reduction in oxidation of cytochrome $a_{3}$. This effect was not apparent in our study and may reflect the differences in extent of hypothermia, and/or rewarming protocols.

duPlessis et al. ${ }^{27}$ used a Hamamatsu NIRO 500 to study 63 infants (aged one day to nine months) undergoing deep hypothermic (less than $18^{\circ} \mathrm{C}$ ) $\mathrm{CPB}$ with circulatory arrest. They report that cytochrome $\mathrm{aa}_{3}$ decreased sharply during the cooling phase. We noted a similar sharp decrease immediately following institution of bypass, which, although it was not seen in the normothermic controls, was not likely associated with cooling as the cytochrome $\mathrm{aa}_{3}$ decrease preceded the cooling period. This was not reported by duPlessis, since they made observations at five- minute intervals. The report also states that the cytochrome $\mathrm{aa}_{3}$ did not return to pre-bypass levels with $60 \mathrm{~min}$ of reperfusion in $52 \%$ of infants. We noticed a similar trend in our patients, with projected return to base line greater than $30 \mathrm{~min}$ following cessation of bypass.

The similarities between our data on children treated with propofol and those from other studies managed with deep hypothermia/continuous flow bypass ${ }^{21}$ suggests that propofol and hypothermia may exert comparable protective effects through maintenance of equilibrium between energy supply and demand at the mitochondrial level. Furthermore, this equilibrium can legitimately be monitored by following changes in the redox status cytochrome $\mathrm{aa}_{3}$.

Our study design did not specify the cooling protocol during bypass or the minimum temperature reached because we had not predicted that temperature would be such a significant factor. Hemodilution during cardiopulmonary bypass is a factor that will ideally be addressed in future studies, as hematocrit, and thus the oxygen-carrying capacity of the blood, may affect the redox status cytochrome $\mathrm{aa}_{3}$. Similarly, $\mathrm{pH}$ is a factor which is likely relevant to cytochrome $\mathrm{aa}_{3}$ equilibrium, 
and therefore should be addressed as a variable in future studies. Also, isoflurane was used in both groups, but not in a controlled fashion. However, comparison of changes between the subgroups of those who received isoflurane and those who did not, within the $\mathrm{P}$ and $\mathrm{C}$ groups, did not demonstrate any appreciable differences in pattern or magnitude of change of redox status of cytochrome based on the use of isoflurane.

No instances of neurological deficit were identified in this study. Duration of bypass differed between the groups, but the median and mean bypass duration was greater in the propofol group, and therefore if there is any bias resulting from this, neurologic sequelae would have been more likely in the propofol than the control group.

Future studies would benefit from increasing the sample size; controlling for extent of hypothermia, perfusion pump priming protocol, temperature and $\mathrm{pH}$; and inclusion of age- appropriate neuropsychological measures to increase the sensitivity of neurological testing to minor deficits.

Conclusions

Monitoring cytochrome $a_{3}$ redox status by NIRS appears technically valid, based on our data which demonstrated no cross-talk with either $\mathrm{Hb}$ or $\mathrm{HbO}_{2}$ signals, and consistent observations within distinct groups and differences between groups.

Children treated with sufficient propofol to achieve EEG burst suppression have a different pattern of change in cytochrome $\mathrm{aa}_{3}$ redox status from controls, and by comparison with other studies, the equilibrium in cytochrome $\mathrm{aa}_{3}$ status achieved with propofol appears comparable to that seen in children managed with moderate to deep hypothermia on continuous flow bypass.

Propofol may offer some cerebral protection during cardiopulmonary bypass surgery in children. It appears to have a positive effect on the cerebral oxygen supply/demand equilibrium. Circumstance under which this effect occurs require further study.

Acknowledgements

We would like to thank the Hospital for Sick Children Foundation (Toronto, Ontario) for supporting this research. We would also like to thank the perfusionists and anesthesiologists at BC's Children's Hospital for their support and assistance during the data collection phase of this project.

\section{References}

1 Ferry PC. Neurologic sequelae of open-heart surgery in children. An 'irritating question'. Am J Dis Child 1990; 144: 369-73.
2 Gilman S. Neurological complications of open heart surgery (Editorial). Ann Neurol 1990; 28: 475-6.

3 Molina JE, Einzig S, Mastri AR, et al. Brain damage in profound hypothermia. Perfusion versus circulatory arrest. J Thorac Cardiovasc Surg 1984; 87: 596-604.

4 Tharion J, Johnson DC, Celermajer JM, Hawker RM, Cartmill TB, Overton JH. Profound hypothermia with circulatory arrest. Nine years' clinical experience. J Thorac Cardiovasc Surg 1982; 84: 66-72.

5 Wernovsky G, Jonas RA, Hickey PR, du Plessis AJ, Newburger JW. Clinical neurologic and developmental studies after cardiac surgery utilizing hypothermic circulatory arrest and cardiopulmonary bypass. Cardiol Young 1993; 3: 308-16.

6 Stump DA. Selection and clinical significance of neuropsychologic tests. Ann Thorac Surg 1995; 59: $1340-4$.

7 Newburger JW, Jonas RA, Wernovsky G, et al. A comparison of the perioperative neurologic effects of hypothermic circulatory arrest versus low-flow cardiopulmonary bypass in infant heart surgery. New Eng J Med 1993; 329: 1057-64.

8 Volpe JJ. Brain injury and infant cardiac surgery: overview. In: Jonas RA, Newburger JW, Volpe JJ (Eds.). Brain Injury and Pediatric Cardiac Surgery. Boston: Butterworth-Heinemann, 1996: 1-10.

9 Nussmeier NA, Arlund C, Slogoff S. Neuropsychiatric complications after cardiopulmonary bypass: cerebral protection by a barbiturate. Anesthesiology 1986; 64: 165-70.

10 Woodcock TE, Murkin JM, Farrar JK, Tweed WA, Guiraudon GM, McKenzie FN. Pharmacological EEG suppression during cardiopulmonary bypass: cerebral hemodynamic and metabolic effects of thiopental or isoflurane during hypothermia and normothermia. Anesthesiology 1987; 67: 218-24.

11 Smith I, White PF, Nathanson M, Gouldson R. Propofol. An update on its clinical use. Anesthesiology 1994; 81: 1005-43.

12 Borgeat A, Wilder-Smith OHG, Suter PM. The nonhypnotic therapeutic applications of propofol. Anesthesiology 1994; 80: 642-56.

13 Stephan H, Sonntag H, Schenk HD, Koblhausen S. Effects of disoprivan on cerebral blood flow, cerebral oxygen consumption and cerebral vascular reactivity. (German) Anesthetist 1987; 36: 60-5.

14 Vandesteene A, Trempont V, Engelman E. Effect of propofol on cerebral blood flow and metabolism in man. Anaesthesia 1988; 43(Suppl): 42-3.

15 Newman MF, Murkin JM, Roach G, et al. Cerebral physiologic effects of burst suppression doses of propofol during nonpulsatile cardiopulmonary bypass. Anesth Analg 1995; 81: 452-7. 
16 Laycock GJA, Mitchell IM, Paton RD, Donaghey SF, Logan RW, Morton NS. EEG burst suppression with propofol during cardiopulmonary bypass in children: a study of the haemodynamic, metabolic and endocrine effects. Br J Anaesth 1992; 69: 356-62.

17 Matta BF, Lam AM. Nitrous oxide increases cerebral blood flow velocity during pharmacologically induced EEG silence in humans. J Neurosurg Anesthesiol 1995; 7: 89-93.

18 Brazy JE. Near-infrared spectroscopy. Clin Perinatol 1991; 18: 519-34.

19 Cope M. The development of near infrared spectroscopy system and its application for non invasive monitoring of cerebral blood and tissue oxygenation in the newborn infant. PhD Thesis, Department of Medical Physics and Bioengineering, University College London, 1991.

20 Jobsis FF. Noninvasive, infrared monitoring of cerebral and myocardial oxygen sufficiency and circulatory parameters. Science 1977; 198: 1264-7.

21 Greeley WJ, Bracey VA, Ungerleider RM, et al. Recovery of cerebral metabolism and mitochondrial oxygenation state is delayed after hypothermic circulatory arrest. Circulation 1991; 84(5S): III400-6.

22 Kurth CD, Steven JM, Nicolson SC, Chance B, Delivoria-Papadopoulos $M$. Kinetics of cerebral deoxygenation during deep hypothermic circulatory arrest in children. Anesthesiology 1992; 77: 656-61.

23 Gagnon RE, Gagnon FA, Macnab AJ. Comparison of 13 published cytochrome c oxidase near-infrared spectroscopy algorithms. Eur J Appl Physiol 1996; 74: 487-95.

24 Benaron DA, Kurth CD, Steven JM, DelivoraPapadopoulos $M$, Chance B. Transcranial optical path length in infants by near-infrared phase-shift spectroscopy. J Clin Monit 1995; 11: 109-17.

25 Duncan A, Meek JH, Clemence M, et al. Optical pathlength measurements on adult head, calf and forearm and the head of the newborn infant using phase resolved optical spectroscopy. Phys Med Biol 1995; 40: 295-304.

26 Tamura $M$. Non-invasive monitoring of brain oxygen metabolism during cardiopulmonary bypass by nearinfrared spectrophotometry. Jpn Circ J 1991; 55: 330-5.

27 DuPlessis AJ, Newburger J, Jonas RA, et al. Cerebral oxygen supply and utilization during infant cardiac surgery. Ann Neurol 1995; 37: 488-97.

28 Moodley M, Macnab AJ. The status of near infrared spectroscopic measurement of cerebral oxygenation in children. South African Neurology Review, March 1998: 6-12.

29 Matcher SJ, Elwell CE, Cooper CE, Cope M, Delpy DT. Performance comparison of several published tissue near-infrared spectroscopy algorithms. Anal Biochem 1995; 226: 54-68.

30 Korzeniewski B. Regulation of cytochrome oxidase: theoretical studies. Biophys Chem 1996; 59: 75-86.

31 Chance B, Cooper CE, Delpy DT, Reynolds EOR Nearinfrared spectroscopy and imaging of living systems. Phil Trans R Soc Lond B 1997; 352: 643-761. 